Vol. 9, $n^{\circ} 1 \mid 2005$

Varia

\title{
Jean-Claude Vimont, La prison : À l'ombre des hauts
} murs

Paris, Gallimard (coll. « Découverte »), 2004, 128 pp., ISBN 207030194 X

Falk Bretschneider

\section{(2) OpenEdition}

\section{Journals}

Édition électronique

URL : https://journals.openedition.org/chs/403

DOI : $10.4000 /$ chs. 403

ISSN : 1663-4837

\section{Éditeur}

Librairie Droz

Édition imprimée

Date de publication : 1 juillet 2005

Pagination : 154

ISBN : 978-2-600-01014-6

ISSN : 1422-0857

Référence électronique

Falk Bretschneider " Jean-Claude Vimont, La prison : À l'ombre des hauts murs », Crime, Histoire \&

Sociétés / Crime, History \& Societies [En ligne], Vol. 9, n¹ | 2005, mis en ligne le 16 février 2009 consulté le 23 mars 2022. URL : http://journals.openedition.org/chs/403 ; DOI : https://doi.org/ $10.4000 /$ chs. 403

Ce document a été généré automatiquement le 23 mars 2022

(C) Droz 


\title{
Jean-Claude Vimont, La prison : À l'ombre des hauts murs
}

Paris, Gallimard (coll. « Découverte »), 2004, 128 pp., ISBN 207030194 X

\author{
Falk Bretschneider
}

\section{RÉFÉRENCE}

Jean-Claude Vimont, La prison : À l'ombre des hauts murs, Paris, Gallimard (coll. « Découverte »), 2004, 128 pp., ISBN 207030194 X.

1 Une main, un miroir, un visage. Des signes : signes émis, signes reçus pour traverser un mur qui ne se traverse pas. Moyens de communiquer dans un univers où l'on ne communique pas. "À l'ombre des hauts murs » - tel est le titre que Jean-Claude Vimont a donné à sa petite histoire illustrée de l'univers ténébreux de la prison; sur la couverture du livre, un prisonnier nous regarde, nous fait signe.

2 Paru dans la collection "Découverte Gallimard », ce travail se veut une introduction grand public à l'histoire de la prison. Il retrace celle-ci avec beaucoup de soin, commençant par la naissance de la prison sous la Constituante, passant ensuite par les grandes étapes de cette volonté, qui a tant fasciné, d'amender les condamnés par la réclusion et le travail.

On y apprend, en de courts chapitres, les idées principales (les réformes philanthropiques, «la fièvre cellulaire ", l'«humanisation" des peines après l'Occupation); les manifestations architecturales qui y correspondent (les manufactures pénales, le panoptique, l'isolement, l'«étoile»). Chose remarquable: il y est constamment question de la vie quotidienne derrière les " hauts murs ", ce qui permet d'aller au delà de la sobriété du chercheur sans pour autant sombrer dans une sensiblerie maladroite. L'ouvrage offre de surcroît une centaine d'illustrations : les unes touchantes (comme celle montrant deux femmes qui serrent leurs amants détenus dans leur bras, p. 90), les autres suscitant la honte (l'homme cagoulé, p. 46); on se souviendra 
surtout de cette petite série de photographies prises par Henri Manuel entre 1928 et 1932 suite à une demande de l'administration pénitentiaire (pp. 60-63).

4 En «bonus» le lecteur trouvera en annexe quelques témoignages et documents (de Bentham et Tocqueville à Foucault et Perrot), une bibliographie indiquant les références les plus importantes, un glossaire, une chronologie et quelques statistiques.

5 Somme toute: un texte bref qui constitue un excellent exemple de vulgarisation en résumant en une centaine de pages les riches recherches de ces dernières décennies sur les prisons, tout en les remaniant convenablement pour un lectorat non-spécialiste.

\section{AUTEURS}

\section{FALK BRETSCHNEIDER}

EHESS, Paris, bretschn@ehess.fr 